\title{
Development and Validation of HPTLC Method for Estimation of Carbamazepine in Formulations and Its In Vitro Release Study
}

\author{
Rashmin B. Patel, ${ }^{1}$ Mrunali R. Patel, ${ }^{2}$ Kashyap K. Bhatt, ${ }^{2}$ and Bharat G. Patel ${ }^{1}$ \\ ${ }^{1}$ A. R. College of Pharmacy and G. H. Patel Institute of Pharmacy, Sardar Patel University, Vallabh Vidyanagar 388 120, India \\ ${ }^{2}$ Indukaka Ipcowala College of Pharmacy, Sardar Patel University, New Vallabh Vidyanagar 388 121, India
}

Correspondence should be addressed to Rashmin B. Patel, rbp.arcp@gmail.com

Received 31 July 2010; Accepted 18 September 2010

Academic Editor: Irene Panderi

Copyright (C) 2011 Rashmin B. Patel et al. This is an open access article distributed under the Creative Commons Attribution License, which permits unrestricted use, distribution, and reproduction in any medium, provided the original work is properly cited.

\begin{abstract}
A new, simple, and rapid high-performance thin-layer chromatographic method was developed and validated for quantitative determination of Carbamazepine. Carbamazepine was chromatographed on silica gel $60 \mathrm{~F}_{254}$ TLC plate using ethyl acetate-toluenemethanol $(5.0+4.0+1.0 \mathrm{v} / \mathrm{v} / \mathrm{v})$ as mobile phase. Carbamazepine was quantified by densitometric analysis at $285 \mathrm{~nm}$. The method was found to give compact spots for the drug $\left(R_{f}=0.47 \pm 0.01\right)$. The linear regression analysis data for the calibration plots showed good linear relationship with $r^{2}=.9995$ in the concentration range 100-600 ng/spot. The method was validated for precision, recovery, repeatability, and robustness as per the International Conference on Harmonization guidelines. The minimum detectable amount was found to be $16.7 \mathrm{ng} /$ spot, whereas the limit of quantitation was found to be $50.44 \mathrm{ng} / \mathrm{spot}$. Statistical analysis of the data showed that the method is precise, accurate, reproducible, and selective for the analysis of Carbamazepine. The method was successfully employed for the estimation of equilibrium solubility, quantification of Carbamazepine as a bulk drug, in commercially available preparation, and in-house developed mucoadhesive microemulsion formulations and solution.
\end{abstract}

\section{Introduction}

Carbamazepine (CBZ), 5-H-Dibenz [b.f] azepine-5-carboxomide, is widely prescribed as an anticonvulsant, antiepileptic, and antimanic drug. CBZ belongs to class II of the biopharmaceutical classification system [1]. Microemulsion (ME) by virtue of their lipophilic nature and small globule size is widely explored as a delivery system $[2,3]$.

Various methods have been reported for the determination of CBZ in pharmaceutical preparations including spectrophotometric methods [4-8], spectrofluorimetry method [9], gas-liquid chromatography (GC) [10, 11], FTRaman spectroscopy [12], planar chromatography [13], and high performance liquid chromatography (HPLC) [14-24]. Most of the methods reported are highly sophisticated, costly, and time consuming and require special sample preparation. The HPLC technique is excellent with respect to selectivity and sensitivity, but it cannot be used for routine analysis because of their specialty requirement and cost. Further, HPLC-based separation methods may not be suitable for the determination of drug from lipidbased delivery systems such as mucoadhesive microemulsion (MME) formulations. These formulations contain various lipophilic excipients that are not soluble in commonly used organic solvents used in HPLC methods. Further, extraction of drug from such lipophilic excipients may not be achieved easily, and such excipients may get adsorbed on stationary phase. Hence, analysis of CBZ, particularly from lipid-based delivery systems, would be difficult with respect to identification of suitable solvents and stationary phase.

In view of this, high-performance thin layer chromatography- (HPTLC-) based methods could be considered as a good alternative, as they are being explored as an important tool in routine drug analysis. Major advantage of HPTLC is its ability to analyze several samples simultaneously using a small quantity of mobile phase. This reduces time and cost of analysis. In addition, it minimizes exposure risks and significantly reduces disposal problems of toxic organic effluents, thereby reducing possibilities of environment pollution. 
HPTLC also facilitates repeated detection of chromatogram with same or different parameters. Furthermore, in case of HPTLC, there are no restrictions on the choice of solvents and mobile phases; drug and lipophilic excipients can be dissolved in a suitable solvent that would evaporate during spotting on TLC plate, leaving behind analyte as a thin band. Therefore, for such methods, extraction procedure is not required always and could be developed for analyzing drug without any interference from excipients [25-29]. The present paper describes the development and validation of HPTLC method for routine estimation of CBZ from bulk and pharmaceutical dosage forms such as tablets and MME formulations and solution developed in-house and for in vitro release study.

\section{Experimental}

2.1. Apparatus. The HPTLC system (Camag, Muttenz, Switzerland) consisted of Limomat $\mathrm{V}$ autosprayer connected to a nitrogen cylinder, a twin trough chamber $(10 \times 10 \mathrm{~cm})$, a derivatization chamber, and a plate heater. Precoated silica gel $60 \mathrm{~F}_{254}$ TLC plates $(10 \times 10 \mathrm{~cm}$, layer thickness $0.2 \mathrm{~mm}$ (E. Merck KGaA, Darmstadt, Germany) was used as stationary phase. TLC plates were prewashed twice with $10 \mathrm{~mL}$ of methanol and activated at $80^{\circ} \mathrm{C}$ for $5 \mathrm{~min}$ prior to sample application. Densitometric analysis was carried out using a TLC scanner III with winCATS software.

2.2. Reagents and Materials. CBZ pure powder was obtained as gratis sample from Max Pharma (India) with 99.9\% purity. Tablet formulation, Mazetol 100 (Nicholas Piramal India Ltd., India) was obtained commercially with the labeled amounts of $100 \mathrm{mg}$ of CBZ. Labrafac CC (Caprylic/Capric Triglycerides, C8-C10 fatty acids), Labrasol (caprylocaproyl macrogol-8-glyceride), Plurol Oleique (Polyglyceryl 6-dioleate) (Gattefosse Saint-Priest, France) was procured as gratis sample from Gattefosse Asia Ltd. (Mumbai, India). Polycarbophil (AA-1, pharmagrade, molecular weight approximately 3.5 million) was procured as gratis sample from Lubrizol Advance Material India Pvt Ltd. (Mumbai, India). Potassium dihydrogen phosphate, methanol, propylene glycol were purchased from SDfine Chemicals (Ahmedabad, India). Ethanol was purchased from Baroda Chemical Ind. Ltd (Dabhoi, India). Double distilled water was used throughout the study. All other chemicals and solvents were of analytical reagent grade and used as received without further purification.

\subsection{HPTLC Method and Chromatographic Conditions}

2.3.1. Sample Application. The standard and formulation samples of CBZ were spotted on Precoated TLC plates in the form of narrow bands of lengths $6 \mathrm{~mm}$, with $10 \mathrm{~mm}$ from the bottom and left margin and with $9 \mathrm{~mm}$ distance between two bands. Samples were applied under continuous drying stream of nitrogen gas at constant application rate of $150 \mathrm{~nL} / \mathrm{s}$.
2.3.2. Mobile Phase and Migration. Plates were developed using mobile phase consisting of ethyl acetate-toluenemethanol $(5.0+4.0+1.0 \mathrm{v} / \mathrm{v} / \mathrm{v})$. Linear ascending development was carried out in $10 \mathrm{~cm} \times 10 \mathrm{~cm}$ twin trough glass chamber equilibrated with mobile phase. The optimized chamber saturation time for mobile phase was $20 \mathrm{~min}$ at $25 \pm 2^{\circ} \mathrm{C}$. Ten milliliters of the mobile phase $(5 \mathrm{~mL}$ in trough containing the plate and $5 \mathrm{~mL}$ in other trough) was used for each development and allowed to migrate a distance of $70 \mathrm{~mm}$, which required $10 \mathrm{~min}$. After development, the TLC plates were dried completely.

\subsubsection{Densitometric Analysis and Quantitation Procedure.} Densitometric scanning was performed on Camag TLC scanner III in absorbance mode and operated by winCATS planar chromatography version 1.3.4. The source of radiation utilized was deuterium lamp. The spots were analyzed at a wavelength of $285 \mathrm{~nm}$. The slit dimensions used in the analysis were length and width of $5 \mathrm{~mm}$ and $0.45 \mathrm{~mm}$, respectively, with a scanning rate of $20 \mathrm{~mm} / \mathrm{s}$. These are selected as recommended by the CAMAG TLC Scanner III manual. It covers $70 \%-90 \%$ of the application band length, which in the present case is $6 \mathrm{~mm}$. The monochromator bandwidth was set at $20 \mathrm{~nm}$. Concentrations of compound chromatographed were determined from the intensity of diffusely reflected light and evaluated as peak areas against concentrations using linear regression equation.

2.3.4. Preparation of CBZ Standard Stock Solution. Stock solution was prepared by weighing CBZ $(10 \mathrm{mg})$. Weighed powder was accurately transferred to a volumetric flask of $100 \mathrm{~mL}$ and dissolved in and diluted to the mark with methanol to obtain a standard stock solution of CBZ $(100 \mu \mathrm{g} / \mathrm{mL})$.

2.3.5. Method Validation. Validation of the developed HPTLC method was carried out as per the International Conference on Harmonization (ICH) guidelines Q2 (R1) for specificity, sensitivity, accuracy, precision, repeatability, and robustness [30].

2.3.6. Specificity. The specificity of the developed method was established analyzing the sample solutions containing CBZ from MME formulations and marketed tablets in relation to interferences from formulation ingredients. The spot for CBZ in the sample was confirmed by comparing retardation factor $\left(R_{f}\right)$ values of the spot with that of the standard.

2.3.7. Sensitivity. Sensitivity of the method was determined with respect to limit of detection (LOD) and limit of quantification (LOQ). Noise was determined by scanning blank spot (methanol) six times. Series of concentrations of drug solutions (10-600 ng/spot) were applied on plate and analyzed to determine LOD and LOQ. LOD was calculated as 3 times the noise level, and LOQ was calculated as 10 times the noise level. LOD and LOQ were experimentally verified by diluting the known concentrations of CBZ until 
the average responses were approximately 3-10 times the standard deviation (SD) of the responses for six replicate determinations.

2.3.8. Linearity and Calibration Curve. Linearity of the method was evaluated by constructing calibration curves at six concentration levels. Calibration curves were plotted over a concentration range of 100-600 ng/spot. Aliquots of standard working solution of CBZ were applied to the plate $(1,2,3,4,5$, and $6 \mu \mathrm{L} /$ spot $)$. The calibration curves were developed by plotting peak area versus concentrations $(n=$ 6) with the help of the winCATS software.

2.3.9. Accuracy. Accuracy of the method was evaluated by carrying the recovery study at three levels. Recovery experiments were performed by adding three different amounts of standard drug, that is, $80 \%, 100 \%$, and $120 \%$ of the drug, to the preanalyzed MME formulations, solution, and conventional tablets, and the resultant was reanalyzed six times.

2.3.10. Precision. Precision was evaluated in terms of Intraday and Interday precisions. Intraday precision was determined by analyzing sample solutions of CBZ from MME formulations at three levels covering low, medium, and higher concentrations of calibration curve for five times on the same day. Interday precision was determined by analyzing sample solutions of CBZ at three levels covering low, medium, and higher concentrations over a period of seven days $(n=5)$. The peak areas obtained were used to calculate mean and \%RSD (relative SD) values.

2.3.11. Repeatability (System Precision). Repeatability of measurement of peak area was determined by analyzing different amount of CBZ samples covering low, medium, and higher ranges of the calibration curve seven times without changing the position of plate. Repeatability of sample application was assessed by spotting CBZ samples covering similar range of calibration curve seven times and analyzing them once.

2.3.12. Robustness. By introducing small changes in mobile phase composition, its volume, chamber saturation time, and slight change in the solvent migration distance, the effects on the results were examined. Robustness of the method was determined in triplicate at a concentration level of $300 \mathrm{ng} / \mathrm{spot}$ and the mean and \%RSD of peak area was calculated.

\subsection{Application of Developed Method}

2.4.1. Determination of Equilibrium Solubility. Solubility of CBZ in various excipients was determined by shake flask method. An excess of CBZ was added to $1 \mathrm{~g}$ of each of the excipient and vortexed to facilitate the mixing. Mixtures were shaken for $48 \mathrm{~h}$ in a reciprocating water bath shaker maintained at room temperature. After $48 \mathrm{~h}$, each tube was centrifuged at $600 \times \mathrm{g}$ for $10 \mathrm{~min}$, and the insoluble drug was discarded by filtration using a $0.45-\mu \mathrm{m}$ membrane filter. The filtrate was suitably diluted with methanol and concentration of drug was quantified by a developed HPTLC method.

2.4.2. Determination of $p H$-Solubility Profile. Solubility of CBZ in various buffers was determined by shake flask method as described above. Various buffers of $\mathrm{pH}$ ranging from 5.0 to 6.5 , namely, phosphate buffer $\mathrm{pH}$ 5.0, phosphate buffer $\mathrm{pH} 6.0$, and phosphate buffer $\mathrm{pH} 6.5$ were used.

2.4.3. CBZ Formulations. Two MME formulations of CBZ were developed in-house, one by mixing labrasol and plurol oleique in a weight ratio of $3: 1$, with $12 \%$ (wt/wt) Labrafac $\mathrm{CC}$ and $0.50 \%(\mathrm{wt} / \mathrm{wt}$ ) polycarbophil AA-1 (formulation F1: for intranasal delivery of CBZ), and another by mixing labrasol and plurol oleique in a weight ratio of $4: 1$, with $12 \%$ (wt/wt) labrafac CC and $0.50 \%$ (wt/wt) polycarbophil AA-1 (formulation F2: for intranasal delivery of CBZ). Both formulations on dilution with water yield microemulsion with mean particle size less than $41 \mathrm{~nm}$ as determined by photon correlation spectroscopy with in-built Zetasizer (Nano ZS, Malvern Instruments, UK) at $633 \mathrm{~nm}$. Heliumneon gas laser having intensity of $4 \mathrm{~mW}$ was the light source. CBZ solution was prepared by dissolving it in mixture propylene glycol and ethanol weight ratio $7: 3$ (Formulation F3: for both intranasal and intravenous delivery of CBZ). Commercially available tablets of CBZ $100 \mathrm{mg}$ were also used in this investigation to verify the suitability of the method for analysis of CBZ from conventional dosage forms.

2.4.4. Analysis of CBZ in Formulations. Twenty tablets were weighed and finely powdered. Quantity equivalent to $100 \mathrm{mg}$ of drug was weighed accurately and dissolved in $50 \mathrm{~mL}$ methanol. The solution was sonicated for $15 \mathrm{~min}$ and then filtered through Whatman filter paper no. 41. The residue was washed thoroughly with methanol. The filtrate and washings were combined and diluted suitably with methanol to obtain a $1 \mathrm{mg} / \mathrm{mL}$ concentration of CBZ. An aliquot of this solution $(1.0 \mathrm{~mL})$ was further diluted to $10 \mathrm{~mL}$ with methanol to obtain a solution containing $100 \mu \mathrm{g} / \mathrm{mL}$ of CBZ. MME formulations and solution containing $1 \mathrm{mg}$ equivalent of $\mathrm{CBZ}$ were dispersed in $5 \mathrm{~mL}$ of methanol and were treated in a similar manner as that of tablets to obtain a stock solution of $100 \mu \mathrm{g} / \mathrm{mL}$, respectively. On plates, $5 \mu \mathrm{L}$ of these solutions were spotted and analyzed for CBZ content using proposed method as described earlier. The possibility of interference from other components of the tablet formulation in the analysis was studied. Placebo MME formulations were analyzed similarly to study the potential interference.

2.4.5. In Vitro Diffusion Profile of CBZ Formulation. MME formulation of CBZ for intranasal delivery (formulation F1and F2) solution (formulation F3) was evaluated for in vitro release using Franz diffusion cell with a diameter of $10 \mathrm{~mm}$. The temperature of the receiver chamber containing $15 \mathrm{~mL}$ of diffusion media (phosphate buffer, $\mathrm{pH}$ 6.0) was 


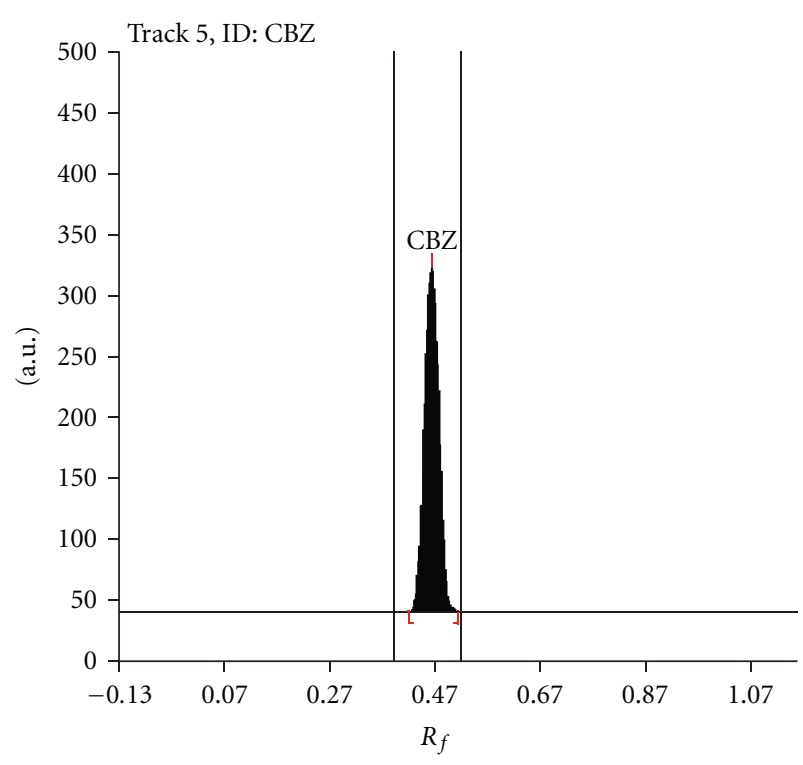

Figure 1: Chromatogram of standard Carbamazepine (500 ng/ spot) using mobile phase ethyl acetate-toluene-methanol $(5.0+4.0$ $+1.0 \mathrm{v} / \mathrm{v} / \mathrm{v})$.

TABLE 1: Linear regression data for the calibration curves $(n=6)$.

\begin{tabular}{lccc}
\hline Range (ng/spot) & $r^{2}$ & Slope \pm SD & Intercept \pm SD \\
\hline $100-600$ & 0.9995 & $9.080 \pm 0.2$ & $2038.23 \pm 45.8$ \\
\hline
\end{tabular}

controlled at $37 \pm 1^{\circ} \mathrm{C}$ under continuous stirring with Tefloncoated magnetic bar at a constant rate, in a way that the nasal membrane surface just flushes the diffusion fluid. During study, $2 \mathrm{~mL}$ of aliquots were removed at $15,30,60,90,120$, and $240 \mathrm{~min}$ and replaced with fresh buffer. Amount of drug released was determined using developed HPTLC method.

\section{Results and Discussion}

To develop HPTLC method of analysis for CBZ for routine analysis, selection of mobile phase was carried out on the basis of polarity. A solvent system that would give dense and compact spots with appropriate and significantly different $R_{f}$ value for CBZ was desired. Various solvent systems such as acetone-methanol, methanol-chloroform, methanol-toluene, methanol-ethyl acetate, toluene-ethyl acetate, toluene-ethyl acetate-methanol, hexane-ethyl acetate, hexane-acetone, toluene-acetonitrile, and tolueneacetonitrile-glacial acetic acid were evaluated in different proportions. Among these, the solvent system comprising of ethyl acetate-toluene-methanol $(5.0+4.0+1.0 \mathrm{v} / \mathrm{v} / \mathrm{v})$ gave good separation of CBZ from its matrix with an $R_{f}$ value of 0.47 . It was also observed that chamber saturation time and solvent migration distance are crucial in chromatographic separation as chamber saturation time of less than $15 \mathrm{~min}$ and solvent migration distances greater than $70 \mathrm{~mm}$ resulted diffusion of analyte spot. Therefore, ethyl acetatetoluene-methanol solvent system in $5.0+4.0+1.0(\mathrm{v} / \mathrm{v} / \mathrm{v})$ proportion with chamber saturation time of $20 \mathrm{~min}$ at $25^{\circ} \mathrm{C}$ and solvent migration distance of $70 \mathrm{~mm}$ was used as mobile phase. These chromatographic conditions produced a welldefined compact spot of CBZ with optimum migration at $R_{f}=0.47 \pm 0.01$ (Figure 1). It also gave a good resolution of analyte from excipients used in various MME formulations, solutions, and marketed tablet formulations.

Under the experimental conditions employed, the lowest amount of drug that could be detected was found to be $16.7 \mathrm{ng} / \mathrm{spot}$ and the lowest amount of drug that could be quantified was found to be $50.44 \mathrm{ng} / \mathrm{spot}$, with RSD $<5 \%$.

Specificity is the ability of an analytical method to assess unequivocally the analyte in the presence of sample matrix. CBZ was separated from excipients with an $R_{f}$ of $0.47 \pm$ 0.01 . There was no interfering peak at the $R_{f}$ value of CBZ from excipients such as labrasol, plurol oleique, labrafac CC, and polycarbophil AA-1 present in MME formulations. In addition, there was no interference from excipients, present in commercial formulation, thereby confirming specificity of method.

Linearity of an analytical method is its ability, within a given range, to obtain test results that are directly, or through a mathematical transformation, proportional to concentration of analyte. Method was found to be linear in a concentration range of 100-600 ng/spot $(n=6)$, with respect to peak area. The regression data as shown in Table 1 reveal a good linear relationship over the concentration range studied demonstrating its suitability for analysis. No significant difference was observed in the slopes of standard curves (ANOVA, $P>.05$ ).

Accuracy of an analytical method is the closeness of test results to true value. It was determined by the application of analytical procedure to recovery studies, where known amount of standard is spiked in preanalyzed samples solutions. Results of accuracy studies from excipient matrix were shown in Table 2; recovery values demonstrated the accuracy of the method in the desired range.

The precision of an analytical method expresses the degree of scatter between a series of measurements obtained from multiple sampling of the same homogeneous sample under prescribed conditions. Intraday precision refers to the use of analytical procedure within a laboratory over a short period of time using the same operator with the same equipment whereas Interday precision involves estimation of variations in analysis when a method is used within a laboratory on different days, by different analysts. The results obtained are shown in Table 3. In all instances, \%RSD values were less than $5 \%$ confirming the precision of the method.

Ten-microliter aliquots of samples containing 100, 300, and $600 \mathrm{ng}$ of CBZ were analyzed according to proposed method. In order to control scanner parameters, that is, repeatability of measurement of peak area, one spot was analyzed without changing position of plate $(n=7)$. By spotting and analyzing the same amount several times $(n=$ 7), precision of automatic spotting device was evaluated. $\%$ RSD was consistently less than 5\% (Table 4 ), which was well below the instrumental specifications, ensuring repeatability of developed method as well as proper functioning of the HPTLC system. 
TABLE 2: Recovery studies $(n=6)$.

\begin{tabular}{|c|c|c|c|c|c|}
\hline Formulation & $\begin{array}{l}\text { Amount of drug } \\
\text { analyzed (ng) }\end{array}$ & $\begin{array}{l}\text { Amount of drug } \\
\text { added (ng) }\end{array}$ & $\begin{array}{c}\text { Theoretical } \\
\text { concentration (ng) }\end{array}$ & $\begin{array}{l}\text { Total amount of drug } \\
\text { analyzed (ng) }\end{array}$ & $\%$ Recovery \pm SD \\
\hline \multirow{4}{*}{$\mathrm{F} 1$} & 200 & 160 & 360 & 360.36 & 100.1 \\
\hline & 200 & 200 & 400 & 405.16 & 101.3 \\
\hline & 200 & 240 & 440 & 437.48 & 99.4 \\
\hline & & & & $\%$ Average recovery $\pm \mathrm{SD}$ & $100.3 \pm 1.3$ \\
\hline \multirow{4}{*}{$\mathrm{F} 2$} & 200 & 160 & 360 & 360.7 & 100.2 \\
\hline & 200 & 200 & 400 & 397.8 & 99.5 \\
\hline & 200 & 240 & 440 & 448.21 & 101.9 \\
\hline & & & & $\%$ Average recovery $\pm \mathrm{SD}$ & $100.5 \pm 1.7$ \\
\hline \multirow{4}{*}{ F3 } & 200 & 160 & 360 & 364.83 & 101.3 \\
\hline & 200 & 200 & 400 & 402.37 & 100.6 \\
\hline & 200 & 240 & 440 & 437.5 & 99.4 \\
\hline & & & & $\%$ Average recovery $\pm \mathrm{SD}$ & $100.5 \pm 1.3$ \\
\hline Marketted & 200 & 160 & 360 & 359.24 & 99.8 \\
\hline \multirow[t]{3}{*}{ Tablets } & 200 & 200 & 400 & 400.35 & 100.1 \\
\hline & 200 & 240 & 440 & 438.31 & 99.7 \\
\hline & & & & $\%$ Average recovery \pm SD & $99.9 \pm 1.9$ \\
\hline
\end{tabular}

TABLE 3: Intra- and interprecision studies $(n=5)$.

\begin{tabular}{llc}
\hline $\begin{array}{l}\text { Amount of drug spotted } \\
(\mathrm{ng})\end{array}$ & $\begin{array}{l}\text { Amount of drug detected } \\
(\mathrm{ng}, \text { mean } \pm \mathrm{SD})\end{array}$ & \%RSD \\
\hline Intraday $(n=5)$ & $98.9 \pm 1.45$ & \\
100 & $300.13 \pm 1.1$ & 1.5 \\
300 & $598.25 \pm 2.01$ & 1.7 \\
600 & & 1.2 \\
\hline Interday $(n=5)$ & $100.21 \pm 0.7$ & \\
100 & $299.05 \pm 1.9$ & 1.8 \\
300 & $600.43 \pm 1.9$ & 2.1 \\
600 & & 1.6 \\
\hline
\end{tabular}

TABLE 4: Repeatability studies $(n=7)$.

\begin{tabular}{|c|c|c|c|}
\hline Parameters & \multicolumn{3}{|c|}{ Amount of drug detected (ng, mean $\pm \mathrm{SD}$ ) } \\
\hline $\begin{array}{l}\text { Amount of } \\
\text { Carbamazepine } \\
\text { spotted (ng) }\end{array}$ & 100 & 300 & 600 \\
\hline $\begin{array}{l}\text { Measurement of } \\
\text { peak area }^{\mathrm{a}}\end{array}$ & $98.44 \pm 3.05$ & $297.8 \pm 3.7$ & $596.49 \pm 5.03$ \\
\hline$\% \mathrm{RSD}$ & 1.28 & 3.32 & 3.06 \\
\hline $\begin{array}{l}\text { Sample application } \\
\text { and derivatization } \\
\text { technique }^{\mathrm{b}}\end{array}$ & $96.9 \pm 3.03$ & $300.11 \pm 1.6$ & $597.17 \pm 3.6$ \\
\hline \%RSD & 1.8 & 2.34 & 1.9 \\
\hline
\end{tabular}

The low values of \%RSD (Table 5) obtained after introducing small deliberate changes in the developed HPTLC method confirmed the robustness of the method.
CBZ has very low water solubility, which limits the development of new pharmaceutical formulations aimed to improve its delivery. Therefore, solubility studies were performed to identify suitable oily phases, surfactants, and cosurfactants that are generally employed in commercially available topical, intranasal, parenteral, and oral products (Table 6). In spite of being lipophilic in nature, CBZ exhibited very low solubility in oily phase such as isopropyl palmitate and miglyols. It was found that only labrafac CC exhibited good solubility for CBZ among the oils studied. The drug exhibited good solubility in labrasol, tween 80 (surfactants), plurol oleique, transcutol P, capmul MCM, and propylene glycol (cosurfactants). Among the various excipients tried, the oily phases such as labrafil M 1944 and labrafac CC exhibited good solubilization potential for CBZ. Labrasol and tween 80 amongst surfactants and plurol oleique, transcutol $\mathrm{P}$ and capmul MCM as a cosurfactant were found to solubilize maximum amount of CBZ.

An understanding of $\mathrm{pH}$-solubility profile of a drug candidate is regarded as one of the most important aspects of preformulation testing for poorly soluble compounds and has been found to be useful topical, intranasal, oral and parenteral formulation development. For example, nasal secretion exhibits a $\mathrm{pH}$ in the range of 4.5-6.5, and the solubility profile of the drug can help in predicting the absorption behavior of that drug molecule in the nasal mucosa. The study indicated that CBZ has adequate solubility and it depends on $\mathrm{pH}$ of the medium (Table 6).

A single spot at $R_{f}=0.47$ was observed in the chromatogram of CBZ. No interference from the excipients present in the marketed tablet formulation was observed. Analysis of CBZ tablets showed a drug content of 99.35 $\pm 1.5 \mathrm{mg}$. The applicability of the method was verified by the determination of CBZ in two MME formulations and 
TABLE 5: Robustness of method $(n=3)$.

\begin{tabular}{llll}
\hline Parameters & $\begin{array}{l}\text { Amount of Carbamazepine spotted } \\
(\mathrm{ng})\end{array}$ & $\begin{array}{l}\text { Amount of Carbamazepine detected } \\
(\mathrm{ng}, \text { mean } \pm \text { SD })\end{array}$ & \%RSD \\
\hline Mobile phase composition: $5.1: 3.9: 1.0$ & 300 & $298.23 \pm 1.7$ & 2.0 \\
Mobile phase composition: $6.9: 4.1: 1.0$ & 300 & $301.1 \pm 1.35$ & 2.3 \\
Mobile phase volume: $8 \mathrm{~mL}$ & 300 & $297.7 \pm 2.06$ & 1.1 \\
Mobile phase volume: $12 \mathrm{~mL}$ & 300 & $295.44 \pm 4.24$ & 2.6 \\
Chamber saturation time: $15 \mathrm{~min}$ & 300 & $298.9 \pm 1.41$ & 1.9 \\
Chamber saturation time: $25 \mathrm{~min}$ & 300 & $300.6 \pm 1.23$ & 2.0 \\
Solvent migration distance: $68 \mathrm{~mm}$ & 300 & $297.7 \pm 3.07$ & 1.6 \\
Solvent migration distance: $72 \mathrm{~mm}$ & 300 & $299.04 \pm 1.9$ & 1.7 \\
\hline
\end{tabular}

TABle 6: Solubility of Carbamazepine in various excipients and buffers.

\begin{tabular}{|c|c|}
\hline Excipients & Solubility ${ }^{\mathrm{a}}$ \\
\hline \multicolumn{2}{|l|}{ Oilyphases } \\
\hline Labrafil M 1944 (Oleoyl polyoxylglycerides) & $37.7 \pm 4.21$ \\
\hline Labrafac CC (Caprylic/Capric Triglycerides) & $10.47 \pm 3.6$ \\
\hline Isopropyl Myristate & $21.9 \pm 3.9$ \\
\hline Labrafac Lipophile (Medium chain triglycerides) & $0.9 \pm 0.7$ \\
\hline Labrafac PG (Propylene glycol dicaprylocaprate) & $1.1 \pm 0.7$ \\
\hline Miglyol 810 (Caprylic/Capric Triglyceride) & $1.31 \pm 1.0$ \\
\hline Miglyol 812 (Caprylic/Capric Triglyceride) & $1.6 \pm 0.9$ \\
\hline $\begin{array}{l}\text { Miglyol } 840 \text { (Propylene Glycol } \\
\text { Dicaprylate/Dicaprate) }\end{array}$ & $0.7 \pm 0.36$ \\
\hline Lauryl Alcohol & $1.8 \pm 0.6$ \\
\hline Isostearylic isostearate & $1.44 \pm 0.6$ \\
\hline Isopropyl Palmitate & $0.35 \pm 0.21$ \\
\hline $\begin{array}{l}\text { Captex } 200 \text { (Propylene Glycol } \\
\text { Dicaprylate/Dicaprate) }\end{array}$ & $3.8 \pm 0.9$ \\
\hline Captex 355 (Glycerol Caprylate Caprate) & $1.8 \pm 0.7$ \\
\hline \multicolumn{2}{|l|}{ Surfactants } \\
\hline Labrasol (Caprylocaproyl Polyoxylglycerides) & $165.8 \pm 6.16$ \\
\hline Tween (Polysorbate) 80 & $75.0 \pm 6.18$ \\
\hline Plurol Stearique WL (Polyglyceryl-6-distearate) & $0.8 \pm 0.15$ \\
\hline Plurol Diisostearique (Polyglyceryl diisostearate) & $1.05 \pm 0.7$ \\
\hline $\begin{array}{l}\text { Cremophor RH } 40 \text { (Polyoxyl } 40 \text { Hydrogenated } \\
\text { Castor Oil) }\end{array}$ & $25.34 \pm 6.11$ \\
\hline \multicolumn{2}{|l|}{ Cosurfactants } \\
\hline Plurol Oleique CC (Polyglyceryl oleate) & $4.13 \pm 1.1$ \\
\hline Plurol Oleique 5203 (Polyglyceryl 6-dioleate) & $1.7 \pm 0.8$ \\
\hline Lauroglycol 90 (Propylene glycol monolaurate) & $49.8 \pm 3.1$ \\
\hline Capryol 90 (Propylene glycol monocaprylate) & $87.44 \pm 5.8$ \\
\hline Transcutol P (Diethylene glycol monoethyl ether) & $157.23 \pm 7.34$ \\
\hline Capmul MCM (Glyceryl Mono- \& dicaprate) & $11.14 \pm 4.1$ \\
\hline Propylene glycol & $150.9 \pm 4.6$ \\
\hline \multicolumn{2}{|l|}{ Aqueous Phases ${ }^{\mathrm{b}}$} \\
\hline Phosphate buffer pH 5.0 & $51.32 \pm 2.9$ \\
\hline Phosphate buffer $\mathrm{pH} 6.0$ & $65.5 \pm 3.42$ \\
\hline Phosphate buffer pH 6.5 & $45.9 \pm 2.28$ \\
\hline
\end{tabular}

TABLE 7: Content of Carbamazepine in various formulations.

\begin{tabular}{lccc}
\hline Formulation & Label claim & $\begin{array}{c}\text { Amount found } \\
(\text { mean } \pm \text { SD })\end{array}$ & \%RSD \\
\hline F1 & $1 \mathrm{mg} / \mathrm{ml}$ & $1.09 \pm 0.21 \mathrm{mg} / \mathrm{ml}$ & 1.3 \\
F2 & $1 \mathrm{mg} / \mathrm{ml}$ & $1.0 \pm 0.26 \mathrm{mg} / \mathrm{ml}$ & 1.2 \\
F3 & $1 \mathrm{mg} / \mathrm{ml}$ & $1.17 \pm 0.15 \mathrm{mg} / \mathrm{ml}$ & 1.1 \\
Tablets & $100 \mathrm{mg} / \mathrm{tablet}$ & $99.35 \pm$ & $1.49 \mathrm{mg} /$ tablet \\
\hline
\end{tabular}

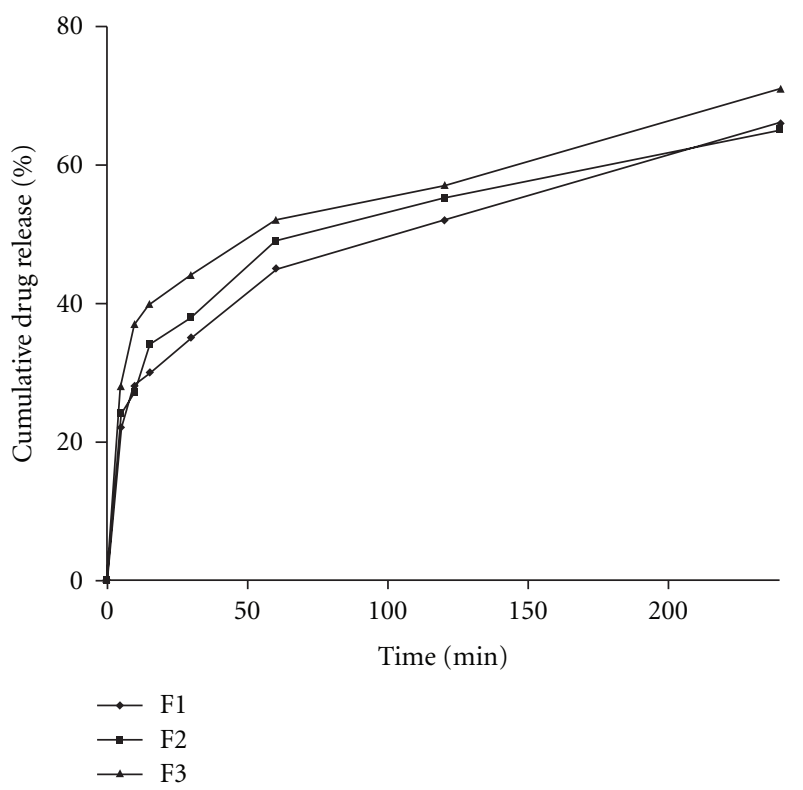

FIGURE 2: In vitro release profiles of Carbamazepine from various formulations in buffer $\mathrm{pH}$ 6.0, data expressed as mean $\pm \mathrm{SD}, n=3$.

solution (developed in-house), and no interference from the excipients matrix was observed. The CBZ content of the developed and the marketed formulations was found to be within the limits $( \pm 5 \%$ of the theoretical value $)$ and are mentioned in Table 7 . The low \%RSD value indicated the suitability of this method for routine analysis of CBZ in various formulations.

In vitro diffusion profile of CBZ Formulation F1, F2, and F3 are presented in Figure 2. Formulation F3 was found 
to exhibit a release of 50\% drug within $30 \mathrm{~min}$ in diffusion media. It was also evident that release of CBZ from MME was consistent with the results of $\mathrm{pH}$-solubility profile study.

The literature describes HPLC method [23] for determination of CBZ in tablet dosage form. The assay results obtained by these methods were used for statistical comparison to evaluate the validity of developed HPTLC method. The calculated $F$ value was found to be 4.9 which is less than the tabulated $F$ value $(8.9)$ at $95 \%(P=.05)$ confidence interval. Therefore, there was no significant difference among the methods $[25,31]$.

\section{Conclusion}

A new HPTLC method has been developed for the identification and quantification of CBZ. Low cost, faster speed, and satisfactory precision and accuracy are the main features of this method. Method was successfully validated as per ICH guidelines and statistical analysis proves that method is sensitive, specific, and repeatable. It can be conveniently employed for routine quality control analysis of CBZ as bulk drug in marketed tablets, MME formulations without any interference from excipients. The method was also applied for the estimation of equilibrium solubility of $\mathrm{CBZ}$ in various excipients and diffusion studies.

\section{Acknowledgments}

The authors are thankful to the All India Council for Technical Education (AICTE; New Delhi, India) for providing the financial assistance for the project, Torrent Pharmaceutical Ltd for the gift sample of CBZ pure powder, Sophisticated Instrumentation Center for Applied Research and Testing (SICART) (Vallabh Vidyanagar, India) for providing facilities for carrying out analytical work, Gattefosse (Saint-Priest, France), Colorcon (Asia) Pvt. Ltd. (Mumbai, India), Abitec Corporation (Janesville, USA), BASF (Mumbai, India), Sasol (Witten, Germany), Lubrizol Advance Material India Pvt. Ltd. (Mumbai, India), Noveon (Cleveland, USA) for providing gratis samples of excipients.

\section{References}

[1] N. S. Barakat, S. A. Omar, and A. A. E. Ahmed, "Carbamazepine uptake into rat brain following intra-olfactory transport," Journal of Pharmacy and Pharmacology, vol. 58, no. 1, pp. 63-72, 2006.

[2] T. K. Vyas, A. K. Babbar, R. K. Sharma, S. Singh, and A. Misra, "Intranasal mucoadhesive microemulsions of clonazepam: preliminary studies on brain targeting," Journal of Pharmaceutical Sciences, vol. 95, no. 3, article 8, pp. 570-580, 2006.

[3] M. J. Lawrence and G. D. Rees, "Microemulsion-based media as novel drug delivery systems," Advanced Drug Delivery Reviews, vol. 45, no. 1, pp. 89-121, 2000.

[4] F. Jaffery, S. N. Ahmad, and B. L. Jailkhani, "A spectrophotometric method for simultaneous estimation of phenytoin and carbamazepine," Journal of Pharmacological Methods, vol. 9, no. 1, pp. 33-39, 1983.
[5] L. E. Riad, K. K. H. Chan, W. E. Wagner Jr., and R. J. Sawchuk, "Simultaneous first- and zero-order absorption of carbamazepine tablets in humans," Journal of Pharmaceutical Sciences, vol. 75, no. 9, pp. 897-900, 1986.

[6] M. S. Cámara, C. Mastandrea, and H. C. Goicoechea, "Chemometrics-assisted simple UV-spectroscopic determination of carbamazepine in human serum and comparison with reference methods," Journal of Biochemical and Biophysical Methods, vol. 64, no. 3, pp. 153-166, 2005.

[7] Z. Rezaei, B. Hemmateenejad, S. Khabnadideh, and M. Gorgin, "Simultaneous spectrophotometric determination of carbamazepine and phenytoin in serum by PLS regression and comparison with HPLC," Talanta, vol. 65, no. 1, pp. 21-28, 2005.

[8] A. J. Fellenberg and A. C. Pollard, "A rapid spectrophotometric procedure for the simultaneous micro determination of carbamazepine and 5,5 diphenyl hydantoin in blood," Clinica Chimica Acta, vol. 69, no. 3, pp. 429-431, 1976.

[9] C. Huang, Q. He, and H. Chen, "Flow injection photochemical spectrofluorimetry for the determination of carbamazepine in pharmaceutical preparations," Journal of Pharmaceutical and Biomedical Analysis, vol. 30, no. 1, pp. 59-65, 2002.

[10] A. Frigerio, K. M. Baker, and G. Belvedere, "Gas chromatographie degradation of several drugs and their metabolites," Analytical Chemistry, vol. 45, no. 11, pp. 1846-1851, 1973.

[11] K. Chen and H. K. Bashi, "Comparative analysis of antiepileptic drugs by gas chromatography using capillary or packed columns and by fluorescence polarization immunoassay," Journal of Analytical Toxicology, vol. 15, no. 2, pp. 82-85, 1991.

[12] M. E. Auer, U. J. Griesser, and J. Sawatzki, "Qualitative and quantitative study of polymorphic forms in drug formulations by near infrared FT-Raman spectroscopy," Journal of Molecular Structure, vol. 661-662, no. 1-3, pp. 307-317, 2003.

[13] S. Mennickent, R. Fierro, M. Vega, M. de Diego, and C. G. Godoy, "Instrumental planar chromatographic method for determination of carbamazepine in human serum," Journal of Separation Science, vol. 32, no. 9, pp. 1454-1458, 2009.

[14] T. D. Cyr, F. Matsui, R. W. Sears, N. M. Curran, and E. G. Lovering, "Liquid chromatographic methods for assay of carbamazepine, 10,11-dihydrocarbamazepine, and related compounds in carbamazepine drug substance and tablets," Journal of the Association of Official Analytical Chemists, vol. 70, no. 5, pp. 836-840, 1987.

[15] M. E. Abdel-Hamid, "Comparative LC-MS and HPLC analyses of selected antiepileptics and beta-blocking drugs," Farmaco, vol. 55, no. 2, pp. 136-145, 2000.

[16] M. K.M. Babu, "Simultaneous separation and quantitation of four antiepileptic drugs - a study with potential for use in patient drug level monitoring," Journal of Pharmaceutical and Biomedical Analysis, vol. 34, no. 2, pp. 315-324, 2004.

[17] M. W. Lam, C. J. Young, R. A. Brain et al., "Aquatic persistence of eight pharmaceuticals in a microcosm study," Environmental Toxicology and Chemistry, vol. 23, no. 6, pp. 1431-1440, 2004.

[18] C. González-Barreiro, M. Lores, M. C. Casais, and R. Cela, "Simultaneous determination of neutral and acidic pharmaceuticals in wastewater by high-performance liquid chromatography-post-column photochemically induced fluorimetry," Journal of Chromatography A, vol. 993, no. 1-2, pp. 29-37, 2003.

[19] R. B. Miller and M. Vranderick, "A validated HPLC method for the determination of carbamazepine and carbamazepine 10,11-epoxide in human plasma," Journal of Liquid Chromatography, vol. 16, no. 6, pp. 1249-1261, 1993. 
[20] E. S. Walker, "Liquid chromatographic determination of carbamazepine in tablets," Journal of the Association of Official Analytical Chemists, vol. 71, no. 3, pp. 523-525, 1988.

[21] N. S. Rajadhyaksha, S. P. Jain, and P. D. Amin, "Carbamazepine: stability indicating HPLC assay method," Analytical Letters, vol. 40, no. 13, pp. 2506-2514, 2007.

[22] A. Owen, J. N. Tettey, P. Morgan, M. Pirmohamed, and B. K. Park, "LC determination of carbamazepine in murine brain," Journal of Pharmaceutical and Biomedical Analysis, vol. 26, no. 4, pp. 573-577, 2001.

[23] F. Demirkaya and Y. Kadioğlu, "Determination of carbamazepine using RP-HPLC method in pharmaceutical preparations," FABAD Journal of Pharmaceutical Sciences, vol. 30, no. 2, pp. 78-82, 2005.

[24] E. K. Oh, E. Ban, J. S. Woo, and C.-K. Kim, "Analysis of carbamazepine and its active metabolite, carbamazepine-10,11epoxide, in human plasma using high-performance liquid chromatography," Analytical and Bioanalytical Chemistry, vol. 386, no. 6, pp. 1931-1936, 2006.

[25] R. B. Patel, M. B. Shankar, M. R. Patel, and K. K. Bhatt, "Simultaneous estimation of acetylsalicylic acid and clopidogrel bisulfate in pure powder and tablet formulations by high-performance column liquid chromatography and highperformance thin-layer chromatography," Journal of AOAC International, vol. 91, no. 4, pp. 750-755, 2008.

[26] R. B. Patel, A. B. Patel, M. R. Patel, M. B. Shankar, and K. K. Bhatt, "Estimation of alprazolam and sertraline in pure powder and tablet formulations by high-performance liquid chromatography and high-performance thin-layer chromatography," Analytical Letters, vol. 42, no. 11, pp. 1588-1602, 2009.

[27] M. R. Patel, R. B. Patel, J. R. Parikh, and B. G. Patel, "HPTLC method for estimation of tazarotene in topical gel formulations and in vitro study," Analytical Methods, vol. 2, no. 3, pp. 275-281, 2010.

[28] R. B. Patel, M. R. Patel, K. K. Bhatt, and B. G. Patel, "HPTLC method development and validation: quantification of paliperidone in formulations and in vitro release study," Analytical Methods, vol. 2, no. 5, pp. 525-531, 2010.

[29] R. B. Patel, M. R. Patel, K. K. Bhari, and B. G. Patel, "Development and validation of an HPTLC method for determination of olanzapine in formulations," Journal of AOAC International, vol. 93, no. 3, pp. 811-819, 2010.

[30] ICH Guideline Q2(R1), "Validation of analytical procedures: text and methodology," November 2005, http://www.ich.org/ LOB/media/MEDIA417.pdf.

[31] R. B. Patel, M. R. Patel, M. B. Shankar, and K. K. Bhatt, "Development and validation of second-derivative spectrophotometry method for simultaneous estimation of Alprazolam and Fluoxetine hydrochloride in pure powder and tablet formulation and its comparison with HPLC method," Eurasian Journal of Analytical Chemistry, vol. 4, no. 1, pp. 7686, 2009. 


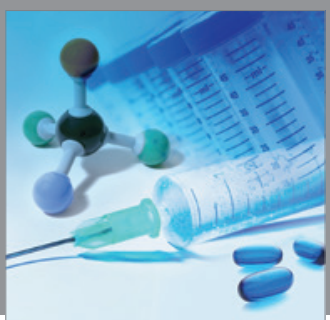

International Journal of

Medicinal Chemistry

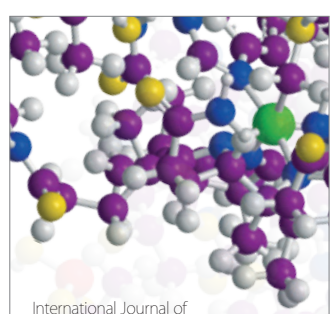

Carbohydrate Chemistry

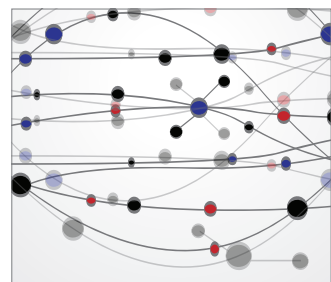

The Scientific World Journal
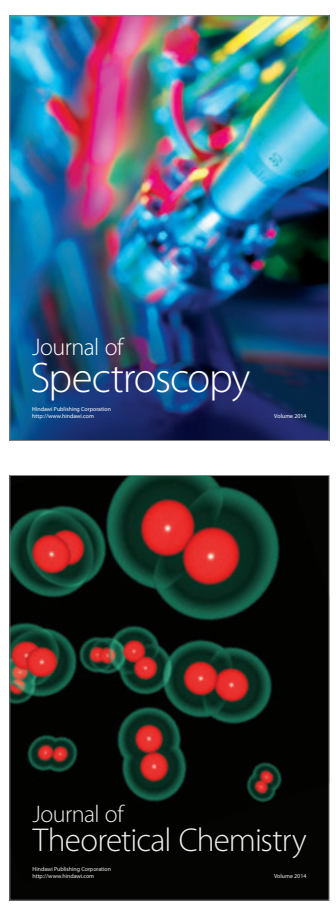
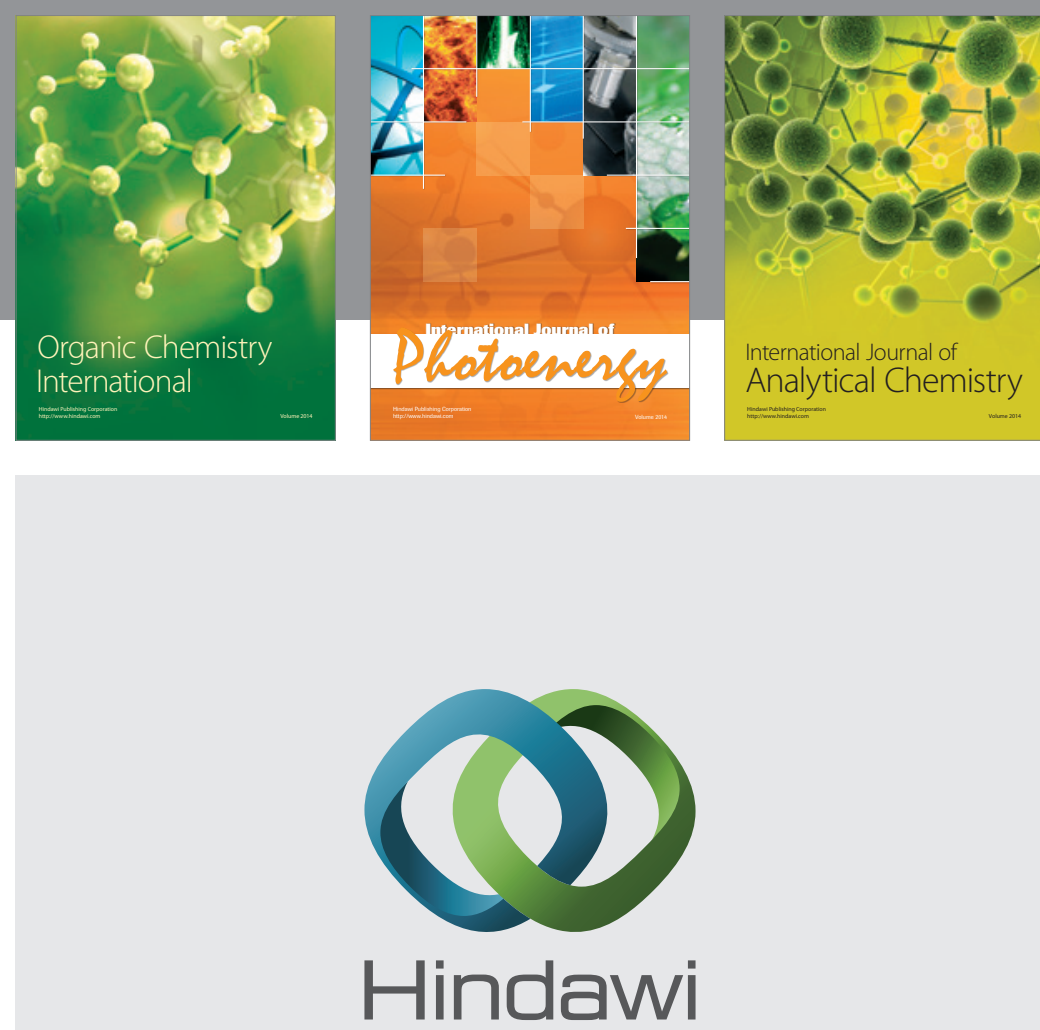

Submit your manuscripts at

http://www.hindawi.com


Journal of

Applied Chemistry
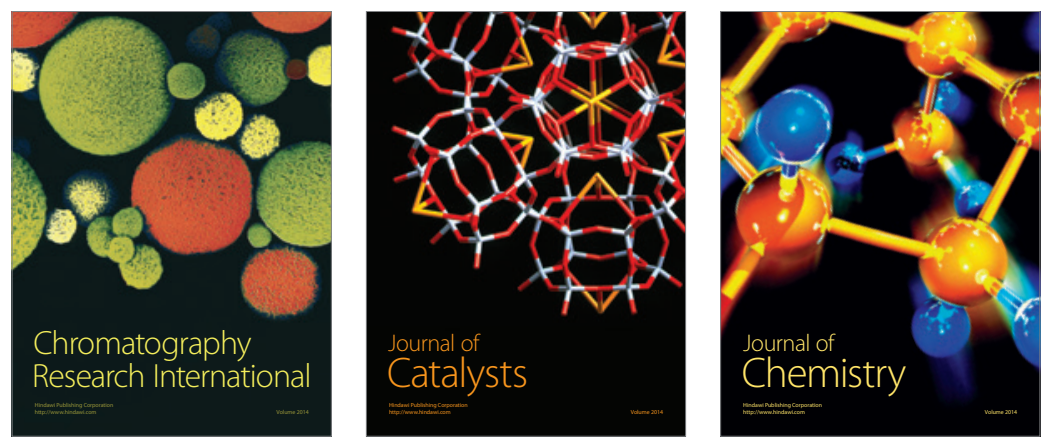
